\title{
Physiological Studies on the Solid-state Quinoa Tempe Fermentation, Using On-line Measurements of Fungal Biomass Production
}

\author{
Walter Peñaloza, Christopher L Davey, John N Hedger and Douglas B Kell* \\ Department of Biological Sciences, University College of Wales, Aberystwyth, Dyfed SY23 3DA, UK
}

(Received 9 October 1991; revised version received 4 December 1991; accepted 6 March 1992)

\begin{abstract}
A quantitative approach to the on-line measurement of fungal biomass, based on the biomass-dependent changes in electrical capacitance at $0.30 \mathrm{MHz}$, was exploited to optimise the solid-substrate tempe fermentation of Chenopodium quinoa Willd by Rhizopus oligosporus Saito. Variables including the mould strain, the initial $\mathrm{pH}$, the inoculum density and the substrate moisture content influenced the mycelial development and quality of quinoa tempe prepared in petri dish fermentation units. It was found that $R$ oligosporus isolate UCW-FF8001 at an inoculation density of $3.5 \times 10^{4}$ colony forming units per gram of quinoa substrate at $620 \mathrm{~g} \mathrm{~kg}^{-1}$ moisture content yielded both the highest biomass and the best quality tempe.
\end{abstract}

Key words: solid-substrate tempe fermentation, Rhizopus oligosporus physiology, cereal food fermentation, biomass measurement, dielectric spectroscopy.

\section{INTRODUCTION}

Tempe is a solid-substrate fermentation of pulses and legumes by the fungus Rhizopus oligosporus Saito, originating in Indonesia but now a focus of investigation in the USA, Europe and Japan (see, for example, Hesseltine et al 1963; Liem et al 1977; Ko and Hesseltine 1979; Wang and Hesseltine 1979; Steinkraus 1983; Samson et al 1987; Nout and Rombouts 1990).

Although solid-substrate fermentation is an older fermentation method than submerged fermentation, it has serious limitations. In a recent review of new developments in tempe research, Nout and Rombouts (1990) pointed out that several important challenges for tempe fermentations, and for solid-substrate fermentations generally, are in the areas of physiology and process engineering development, where a quantitative approach is required to the study of fungal growth kinetics, for mathematical modelling, and for optimising the design of bioreactors and fermentation processes.

A variety of previous studies of tempe have attempted to optimise some of the tempe fermentation variables, eg

* To whom correspondence should be addressed. the temperature of incubation (Hesseltine et al 1963; Kidby et al 1977), inoculum density (Kidby et al 1977), mould strain (Steinkraus et al 1960; Wang and Hesseltine 1966a) and type of substrate (Hesseltine et al 1967). However, assessment of the procedures was based on subjective judgements of the development of mycelium on the substrata, eg 'no visible growth', 'faint growth', 'moderate growth', and 'satisfactory growth ' were terms included in relative scales by these workers.

These approaches have obvious limitations for use in systematic and quantitative studies, especially if the tempe fermentation technique is to be exploited in the future for the production of high value products such as physiologically active compounds (Nout and Rombouts 1990).

Recently, we showed (see Davey et al 1991; Peñaloza et al 1991) that the on-line monitoring of the radiofrequency electrical capacitance, using the Bugmeter ${ }^{\circledR}$ dielectric spectrometer, was a suitable technique for measuring biomass during the solid-substrate tempe fermentation, and that such results were well correlated with the amount of biomass as estimated from hyphal length measurements. Moreover the capacitance measurement allowed the differentiation between biomass and 

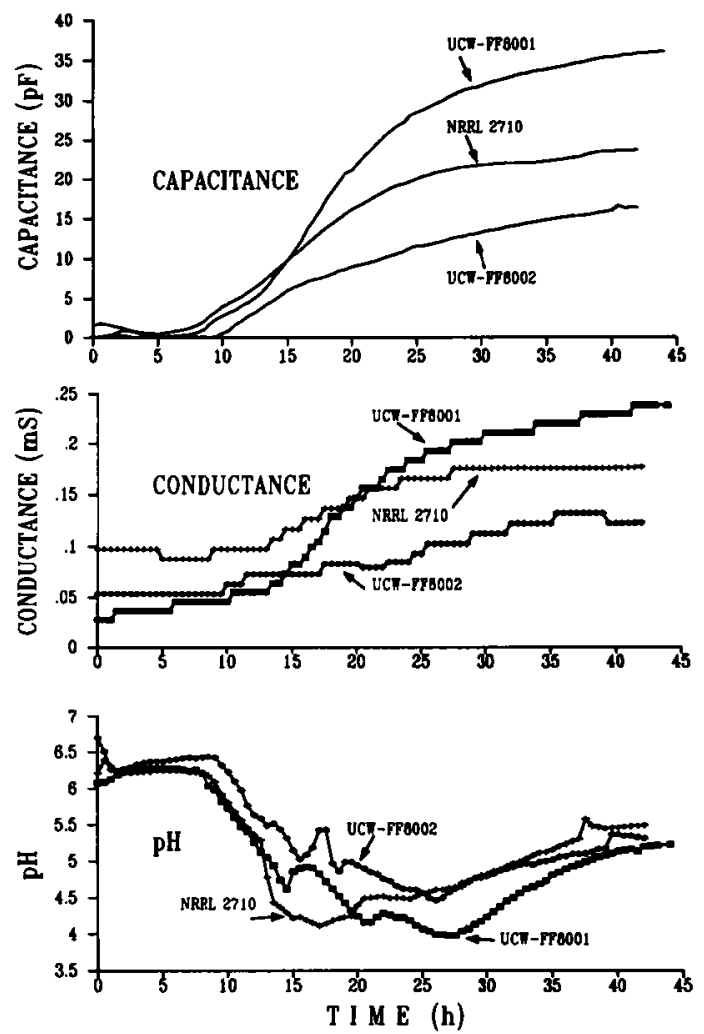

Fig 1. On-line capacitance, conductance and $\mathrm{pH}$ of quinoa during the tempe fermentation using three strains of Rhizopus oligosporus. Quinoa (Chenopodium quinoa Willd), sweet variety, was prepared at a moisture content of $634 \mathrm{~g} \mathrm{~kg}^{-1}$ and a $\mathrm{pH}$ of $6 \cdot 4$, and inoculated with $R$ oligosporus Saito. Strains used were NRRL 2710, UCW-FF8001 and UCW-FF8002 at an inoculum density of $3.5 \times 10^{5} \mathrm{cfu} \mathrm{g}^{-1}$. Capacitance and conductance were monitored on-line with a Bugmeter at $0.30 \mathrm{MHz}$. pH was also monitored. Incubation was at $31^{\circ} \mathrm{C}$.

necromass. It thus became possible to effect a quantitative study of the tempe fermentation of quinoa, in which the growth of the biomass was monitored on-line and in real time via dielectric spectroscopy.

Quinoa (Chenopodium quinoa Willd) has been an indigenous marginal crop in Ecuador and other Andean countries. Recently it has attracted attention as a food crop resource both inside and outside South America (Risi and Galwey 1984; Carruthers 1986; Reichert et al 1986; Mizui et al 1990; Wahli 1990). Quinoa used as a substrate for the tempe fermentation yields a good quality tempe (Robalino and Peñaloza 1988; Peñaloza 1991). Moreover, quinoa is an ideal raw material in that it is easier to prepare than soya beans and other substrates previously investigated for tempe production (Robinson and Kao 1977; Gandjar 1986; Paredes-Lopez et al 1987; Nout and Rombouts 1990).

The aims of this study were to investigate the physiological effects of fermentation variables and to optimise a process for the production of quinoa tempe. The influence of mould strain, inoculum density, $\mathrm{pH}$, moisture and quinoa variety on mycelial biomass in the tempe were studied, and the data are used to suggest an optimal procedure for the production of quinoa tempe.

\section{METHODS}

\section{Preparation of the substrate}

Quinoa, scarified to remove saponins, was kindly supplied by Latinreco SA (Quito, Ecuador). Its preparation involved boiling in a sixfold volumetric excess of tap water $\left(100^{\circ} \mathrm{C}\right)$ for $12 \mathrm{~min}$; the cooking water was drained off and the quinoa was then superficially dried until an overall moisture content (measured gravimetrically) of $600-650 \mathrm{~g} \mathrm{~kg}^{-1}$ (except where stated otherwise) was achieved. The prepared substrate, whose $\mathrm{pH}$ was 6.5 , was stored in a deep freeze at $-18^{\circ} \mathrm{C}$, and thawed as required before each experiment.

Two quinoa varieties were studied: (1) piartal, or sweet quinoa, which is an export crop, and (2) bitter quinoa consisting of a mixture of Ecuadorean ecotypes. Saponins were removed from both quinoas. Different moisture contents were obtained by varying the drying time of the cooked quinoa in a cabinet at $40^{\circ} \mathrm{C}$.

A low-pH quinoa was also prepared by soaking the grain at $25-30^{\circ} \mathrm{C}$ overnight in an excess of tap water including $100 \mathrm{ml}$ litre $\mathrm{e}^{-1}$ of a previous soak water. A vigorous lactic fermentation resulted, and the drained quinoa had a $\mathrm{pH}$ between $5 \cdot 0$ and $5 \cdot 5$.

$R$. oligosporus strains NRRL 2710, UCW-FF8001 and UCW-FF8002 were used to prepare freeze dried inocula (Wang et al 1975), which were added to the substrate at inoculation densities varying from $3.5 \times 10^{3}$ to $3.5 \times 10^{6}$ colony forming units per gram ( $\mathrm{cfu} \mathrm{g}^{-1}$ ). After mixing, approximately $42 \mathrm{~g}$ of the inoculated quinoa was packed in sterile, disposable petri dishes (diameter $8.7 \mathrm{~cm}$ and depth $1.25 \mathrm{~cm}$ ). Five dishes were used per replicate experiment. Incubation was at $31^{\circ} \mathrm{C}$ and at a relative humidity of about $85 \%$.

Petri dishes were used as fermentation containers following initial comparative studies on conventional commercial methods based on perforated plastic bags, covered trays, and perforated metal containers (Steinkraus 1983; Nout and Rombouts 1990). These studies showed that there was a similar fermentation pattern in all four systems. The advantage of the petri dish system was felt to be its reproducibility and greater homogeneity compared with the other three methods.

The monitoring of the fermentation of quinoa for tempe was carried out using a computerised arrangement described in detail elsewhere (see Davey et al 1991; Peñaloza et al 1991). The theory behind this method of monitoring biomass is also given in detail in a number of publications (Harris et al 1987; Kell et al 1990; Markx and Kell 1990; Markx et al 1991). The electrical capacitance in picofarads $(\mathrm{pF})$ and the conductance in 
milliSiemens (mS) were monitored at $0.30 \mathrm{MHz}$ using a probe containing four gold pin-type electrodes in an insulating matrix, which was connected to a Bugmeter Biomass Monitor (Aber Instruments Ltd, Aberystwyth). The probe was inserted into the substrate in such a way that a constant depth of $10 \mathrm{~mm}$ was left between the bottom of the disposable dish and the body of the probe.

The cell constant, as measured using $10 \mathrm{mM} \mathrm{KCl}$, was $0.65 \mathrm{~cm}^{-1}$. A pH electrode was inserted into an adjacent plate. Probes were connected as appropriate to a digital $\mathrm{pH}$ meter and a Bugmeter, and thence to a Blackstar 2308 analog-to-digital interface. Data were logged into an Opus PC-II (XT-compatible) microcomputer. At the start of incubation, the frequency of operation of the Bugmeter was set at $0.30 \mathrm{MHz}$, the capacitance $(\mathrm{pF})$ was backed off to zero and the increments or delta capacitance $(\triangle C)$ were logged every $30 \mathrm{~min}$, together with the conductance $(\mathrm{mS})$ and $\mathrm{pH}$. At the end of the incubation period, data were recovered and analysed using a spreadsheet method (Davey et al 1990).

Samples were periodically removed from replicate plates for off-line analysis of $\mathrm{pH}$ and moisture content. Hyphal length and dry weight losses were also determined by methods previously described (Davey et al 1991; Peñaloza et al 1991). Finally, the general characteristics of fresh quinoa tempe were assessed by subjective observations of appearance, degree of sporulation, flavour and texture. The degree of sporulation was assessed as the extent of grey to black zones of sporangium production on the cake surface. In commercial production, sporulated tempe is normally considered to be undesirable.

\section{RESULTS AND DISCUSSION}

\section{Influence of Rhizopus oligosporus strains on fermentation characteristics}

All three strains gave a consistently good quality tempe. Figure 1 shows typical fermentations for each of the three strains studied, from which it may be inferred that the largest changes in capacitance, conductance and $\mathrm{pH}$ occurred in the fermentation using strain UCW-FF8001. The extent of mycelial growth, as measured in terms of the electrical capacitance, was correlated with the hyphal length estimated for each individual strain of $R$ oligosporus, as shown in Fig 2. This confirms the usefulness of the dielectric technique for biomass estimation in solidsubstrate fermentations. Associations could also be found between changes in the capacitance, hyphal length, moisture and dry weight loss of the quinoa. However, each strain had different fermentation characteristics (Figs 1 and 2).

Strain UCW-FF8002 sporulated less and late, a phenomenon probably associated with the lower growth

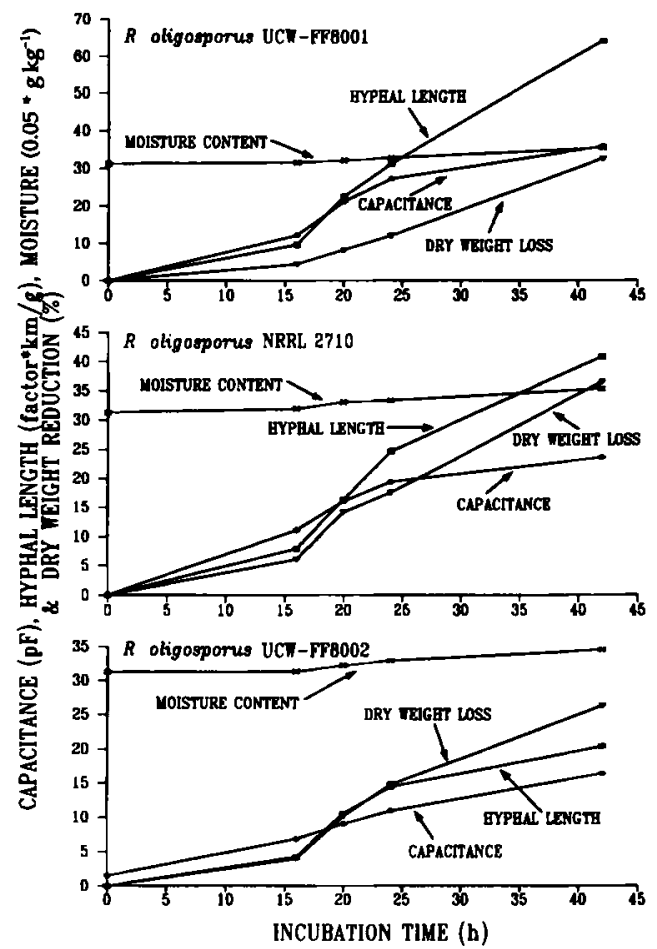

Fig 2. Changes in hyphal length, moisture content, dry weight loss and capacitance during the growth of three isolates of Rhizopus oligosporus on quinoa during the tempe fermentation. Experimental conditions were exactly the same as described in the legend to Fig 1. Capacitance data were read from the online output given in Fig 1, but only at the times when replicate samples were taken out for off-line analysis. Hyphal length $\left(\mathrm{km} \mathrm{g}^{-1}\right.$ of dry tempe) was multiplied by a factor for plotting purposes, as follows: for strain UCW-FF8001 the factor is 6 ; for both NRRL 2710 and UCW-FF8002 the factor is 3.8 . Moisture content $\left(\mathrm{g} \mathrm{kg}^{-1}\right)$ and dry weight reduction or loss $(\%)$ were determined as described in the Methods section. Linear regression analysis showed that capacitance $(C$, in $\mathrm{pF})$ was significantly associated with hyphal length $\left(H L\right.$, in $\mathrm{km} \mathrm{g}^{-1}$ dry tempe) for each strain of $R$ oligosporus as follows:

NRRL 2710: $C=4.5+1.98 H L r^{2}=87 \% \quad P=0.021$

UCW-FF8001: $C=5.8+3.16 H L r^{2}=89 \% P=0.016$

UCW-FF8002: $C=2.4+1.99 H L r^{2}=96 \% P=0.004$

Analysis of variance on the above relationships showed that the regressions of capacitance on hyphal length for strains UCW. FF8001 and UCW-FF8002 were significantly different from each other at the level of $P=0.05$. The other relationships (between NRRL 2710 and UCW-FF8002, and UCW-FF8001 and NRRL 2710) were not significantly different.

rate (as observed in terms of both capacitance and hyphal length changes) than strains UCW-FF8001 and NRRL 2710. The latter caused the greatest fall in $\mathrm{pH}$ at $15 \mathrm{~h}$, an advantage in limiting contaminant bacterial growth of the type often found in soya tempe (Tanaka et al 1985; Nout et al 1987a,b, 1988; Samson et al 1987; Mulyowidarso et al 1990).

Strain UCW-FF8002 had the lowest hyphal length and dry weight reduction, ie $6.8 \mathrm{~km} \mathrm{~g}^{-1}$ and $26.3 \%$ respectively, after incubation at $31^{\circ} \mathrm{C}$ for $42 \mathrm{~h}$. Strains NRRL 2710 and UCW-FF8001 had similar hyphal 

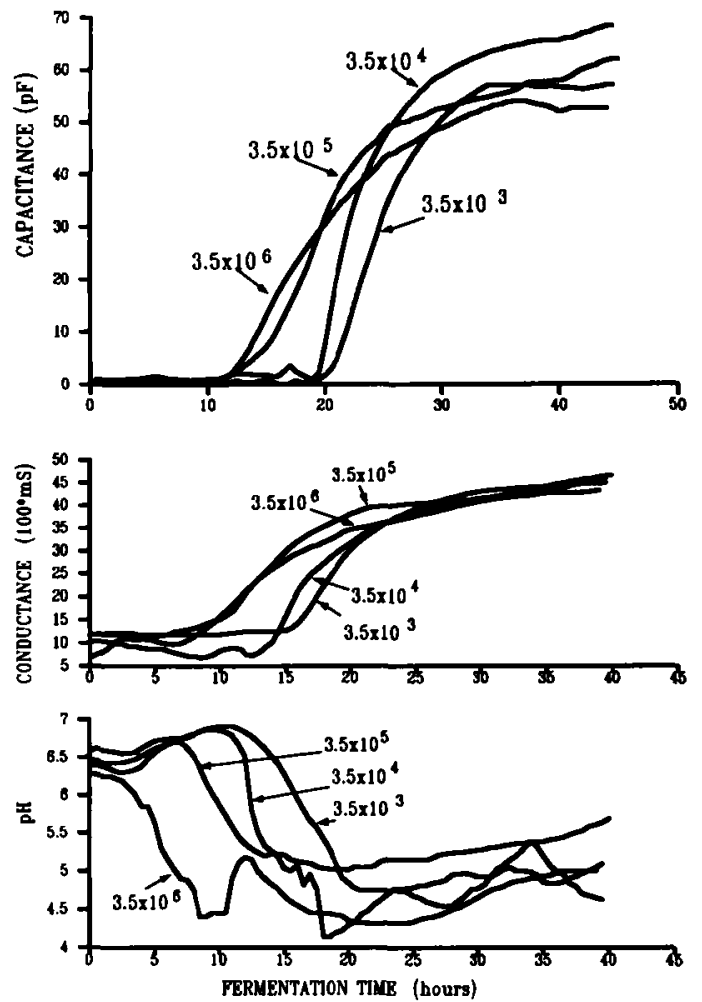

Fig 3. Time courses of on-line capacitance, conductance and $\mathrm{pH}$ during the quinoa tempe fermentation using different inoculum densities. Quinoa (sweet variety) containing, after preparation, a moisture content of $655 \mathrm{~g} \mathrm{~kg}^{-1}$ and $\mathrm{pH}$ about 6.5 was inoculated with $R$ oligosporus UCW-FF8001 at densities ( $\mathrm{cfu} \mathrm{g}^{-1}$ ) shown and incubated at $31^{\circ} \mathrm{C}$. The monitoring was exactly the same as described in the legend to Fig 1.

lengths, about $11 \mathrm{~km} \mathrm{~g}^{-1}$, and dry weight loss, about $37 \%$, after incubation for the same period. However, the higher capacitance exhibited by strain UCW-FF800I compared with that of strain NRRL 2710 was not reflected in a proportionately greater hyphal length. It is reasonable to conclude that differences in the mycelial morphologies (chiefly the extent of branching and the hyphal diameter) may account for changes in the capacitance : hyphal length ratio of different strains, since the signal per unit biomass (biovolume) of the dielectric technique depends on the radius of the sphere of equivalent radius of the cells of interest (Harris et al 1987). Indeed just a small difference in hyphal diameter will have a considerable impact on the surface area of the plasma membrane of the $R$ oligosporus hyphae.

\section{Effect of inoculum density of the quinoa tempe fermentation}

The effect of the inoculum density of $R$ oligosporus on the changes in capacitance, conductance and $\mathrm{pH}$ in the fermentation is shown in Fig 3. Accurate dosage of inoculum and homogeneous mixing are usually con- sidered to be important in tempe production (Nout and Rombouts 1990), but the effect of inoculum density on the fermentation has not been precisely established. For example Wang et al (1975) suggested an inoculation density of $1 \times 10^{4}$ viable counts $\mathrm{g}^{-1}$ of cooked grain, whereas Ko and Hesseltine (1979) reported that an inoculum of $1 \times 10^{5}-1 \times 10^{6}$ spores $\mathrm{g}^{-1}$ of initial dry soya bean gave successful results in pilot plant trials. Kidby $e t$ al (1977) found that a satisfactory tempe could be made from lupins using a wide range of inoculum levels, viz $1.8 \times 10^{2}$ to $7.8 \times 10^{5}$ spores $\mathrm{g}^{-1}$ of dry beans. In the present experiments we studied inoculum densities in the range of $3.5 \times 10^{3}$ to $3.5 \times 10^{6} \mathrm{cfu}^{-1}$, and observed that the inoculum size has a substantial effect on the progress of the tempe fermentation of quinoa (Fig 3).

The onset of the fermentation, ie the rise of both capacitance and conductance and the fall of $\mathrm{pH}$ (Fig 3) is greatly shortened when the inoculum concentration increases from $3.5 \times 10^{3}$ to $3.5 \times 10^{6} \mathrm{cfu}^{-1}$. Thus, at an inoculum density of $3.5 \times 10^{6} \mathrm{cfu}^{-1}$ the lag phase $\left(t_{\text {lag }}\right)$ was only $10 \mathrm{~h}$, whereas at an inoculum density of $3.5 \times 10^{3} \mathrm{cfu}^{-1}$ the lag phase was twice as long. Williams and Wood (1986) studied the effect of inoculum size on Aspergillus ochraceus and $A$ flavus respectively. These authors, using low-frequency impedimetric techniques, also found that the detection time decreased as the inoculum density increased.

The spore germination rate in fungi has been shown to be dependent upon spore population density, and selfinhibitors and self-stimulators of spore germination and germ-tube extension have been described in several fungi (Robinson 1978; Cotter 1981). As the concentration of spores increases so will the concentration of factors acting on spore germination, and the presence of a germination-stimulating compound could be the cause of the increased germination at the higher inoculum densities. In contrast, Kidby et al (1977) concluded that at $7.8 \times 10^{5}$ spores $\mathrm{g}^{-1}$ dry beans, no lupin tempe was produced due to self-inhibitory activity.

Whilst the lag phase was longer for the two lower inoculum densities, the maximum specific growth rate during the fermentation was actually greater (Fig 3). However, the final fungal biomass, as measured by capacitance after $40 \mathrm{~h}$ incubation at $31^{\circ} \mathrm{C}$, was not dissimilar (about $50-70 \mathrm{pF}$ ) at the different inoculum densities (Fig 3), whilst the change in conductance was virtually independent of inoculum density. Williams and Wood (1986) also found that, after an incubation of about $42 \mathrm{~h}$, the impedance change elicited at different inoculum densities was nearly the same using $A$ ochraceus and $A$ flacus. This could mean that the mycelium of $R$ oligosporus is capable of achieving a similar volume fraction at each of the inoculum densities. However, the hyphal lengths attained seemed to be proportional to inoculum size, especially in quinoa tempe incubated for only $24 \mathrm{~h}$ (see Table 1). At this incubation time, with an inoculum density of $3.5 \times 10^{3} \mathrm{cfu}^{-1}$ the growing my- 
TABLE 1

Effect of inoculum density of Rhizopus oligosporus UCW-FF8001 on several parameters of quinoa tempe fermentation

\begin{tabular}{|c|c|c|c|c|c|c|c|c|c|}
\hline \multirow{2}{*}{$\begin{array}{c}\text { Inoculum } \\
\text { density } \\
\left(c f u g^{-1}\right)\end{array}$} & \multirow{2}{*}{$\begin{array}{c}\text { Lag } \\
\text { phase } \\
(h)\end{array}$} & \multicolumn{4}{|c|}{$24 \mathrm{~h}$ incubation } & \multicolumn{4}{|c|}{$44 h$ incubation } \\
\hline & & $\begin{array}{c}\mathrm{C} \\
(p F)\end{array}$ & $\begin{array}{c}\text { Hyphal } \\
\text { length } \\
\left(k m g^{-1}\right)\end{array}$ & $\begin{array}{c}\text { Dry wt loss } \\
(\%)\end{array}$ & $\begin{array}{c}\text { Moisture } \\
\left(g k g^{-1}\right)\end{array}$ & $\begin{array}{c}\mathrm{C} \\
(p F)\end{array}$ & $\begin{array}{c}\text { Hyphal } \\
\text { length } \\
\left(k m g^{-1}\right)\end{array}$ & $\begin{array}{c}\text { Dry wt loss } \\
(\%)\end{array}$ & $\begin{array}{c}\text { Moisture } \\
\left(g k g^{-1}\right)\end{array}$ \\
\hline \multicolumn{10}{|c|}{ Sweet quinoa } \\
\hline $3.5 \times 10^{3}$ & 20 & $25 \cdot 3$ & $2 \cdot 6$ & $3 \cdot 3$ & 631 & 57.0 & $9 \cdot 7$ & 16.0 & 663 \\
\hline $3.5 \times 10^{4}$ & 16 & $42 \cdot 5$ & $3 \cdot 6$ & $5 \cdot 6$ & 640 & $68 \cdot 2$ & $12 \cdot 3$ & $23 \cdot 3$ & 682 \\
\hline $3.5 \times 10^{5}$ & 12 & $45 \cdot 4$ & 5.9 & $10 \cdot 4$ & 647 & $61 \cdot 8$ & $13 \cdot 4$ & $28 \cdot 3$ & 705 \\
\hline $3.5 \times 10^{6}$ & 10 & $40 \cdot 0$ & $10 \cdot 6$ & $14 \cdot 4$ & 665 & $52 \cdot 6$ & $15 \cdot 0$ & $29 \cdot 2$ & 707 \\
\hline \multicolumn{10}{|c|}{ Bitter quinoa } \\
\hline $3.5 \times 10^{3}$ & 21 & $10 \cdot 2$ & $2 \cdot 8$ & 8.8 & 694 & $27 \cdot 4$ & $9-5$ & $34 \cdot 4$ & 764 \\
\hline $3.5 \times 10^{4}$ & 17 & $17 \cdot 9$ & $7 \cdot 3$ & $12 \cdot 8$ & 703 & 31.6 & $11 \cdot 6$ & $38 \cdot 6$ & 776 \\
\hline $3.5 \times 10^{5}$ & 10 & $16 \cdot 0$ & $9 \cdot 1$ & $18 \cdot 7$ & 704 & $20 \cdot 9$ & $14 \cdot 3$ & $36 \cdot 2$ & 757 \\
\hline
\end{tabular}

Chenopodium quinoa varieties sweet (at a moisture content of $625 \mathrm{~g} \mathrm{~kg}^{-1}$ and $\mathrm{pH}$ about 6.5 ), and bitter (at a moisture content of $655 \mathrm{~g} \mathrm{~kg}^{-1}$ and $\mathrm{pH}$ 6.5) were inoculated with $R$ oligosporus UCW-FF8001 at the densities shown. Other experimental conditions are given in the legend to Fig 3. Data for capacitance $(C)$ in picoFarads $(\mathrm{pF})$ and the length of the lag phase were derived from on-line capacitance courses. Hyphal length in $\mathrm{km} \mathrm{g}^{-1}$ of dry tempe, dry weight loss in \% and moisture content in $\mathrm{g} \mathrm{kg}^{-1}$ were determined off-line on samples of quinoa tempe incubated at $31^{\circ} \mathrm{C}$ for 24 and $44 \mathrm{~h}$.

celium possessed only $2.6 \mathrm{~km}$ hyphal length per gram of dry tempe $\left(\mathrm{km} \mathrm{g}^{-1}\right)$ which was significantly lower than the $10.6 \mathrm{~km} \mathrm{~g}^{-1}$ obtained at an inoculum density of $3.5 \times 10^{6} \mathrm{cfu}^{-1}$ of prepared substrate. Similarly, the dry weight loss of quinoa tempe increased from $3.3 \%$ to $14.4 \%$ of quinoa with this change in inoculum size (Table 1).

One possibility to consider is that at high inoculum densities oxygen becomes a strongly growth-controlling factor and/or that there is at least an effect on hyphal diameter. Gow (1989) showed the widening effect of oxygen on hyphae grown in a gradient of limiting oxygen. It is reasonable to assume that, at a given incubation time, there is more oxygen available with a low inoculum density, and thus hyphae might be wider than those at high inoculum densities where competition might stimulate the apical extension of hyphae at the expense of their diameters. The diameter of hyphae at the different inoculation densities was not measured in this investigation, but could, as noted earlier, have influenced the capacitance data.

The influence of inoculum concentration on the quality of quinoa tempe was also noticeable, especially in terms of sporulation, cake appearance and compactness. At an inoculum concentration of $3.5 \times 10^{3} \mathrm{cfu} \mathrm{g}^{-1}$ (and lower; data not shown), quinoa seeds were covered only by loose mycelium after $24 \mathrm{~h}$ incubation (the normal harvesting time). However, at inoculum densities of $3.5 \times 10^{4} \mathrm{cfu} \mathrm{g}^{-1}$ and higher, the tempe became increasingly firm and of a very good eating quality. The extent of sporulation of the tempe was proportional to inoculum density. At the higher inoculum densities of
$3.5 \times 10^{5}$ and $3.5 \times 10^{6} \mathrm{cfu} \mathrm{g}^{-1}$ sporulation increased from the edges to the centre of the petri dish after $24 \mathrm{~h}$.

In the day-to-day operation of a large-scale tempe production system, the fermentation time is an important issue and could be substantially reduced by the use of high inoculum densities. Moreover the rapid drop of $\mathrm{pH}$ in quinoa could be an additional advantage in creating conditions unfavourable for bacterial growth. However, the negative aspect of high inoculum density is the early and heavy sporulation of the tempe, an important marketing factor (Nout et al 1985).

The optimum inoculum density for the fermentation of quinoa for tempe would thus seem to be around $3.5 \times 10^{4} \mathrm{cfu}^{-1}$, which coincides with the inoculum size recognised as the most suitable elsewhere for tempe made from other substrates (Wang et al 1975; Kidby et al 1977; Ko and Hesseltine 1979; Nout and Rombouts 1990).

\section{The effect of the initial pH on the quinoa tempe fermentation}

The influence of two initial $\mathrm{pH}$ values, $5 \cdot 0$ and $6 \cdot 5$, on the tempe fermentation of quinoa with $R$ oligosporus UCWFF8001 inoculated with $3.5 \times 10^{3} \mathrm{cfu}^{-1}$ is shown in Fig 4. The importance of the substrate $\mathrm{pH}$ prior to inoculation with the tempe mould, as a means of controlling bacterial spoilage of tempe, was advocated by Steinkraus et al (1960). More recent investigations (Ko and Hesseltine 1979; Tanaka et al 1985; Nout et al 1985, 1987b, 1988; Samson et al 1987; Ashenafi and 

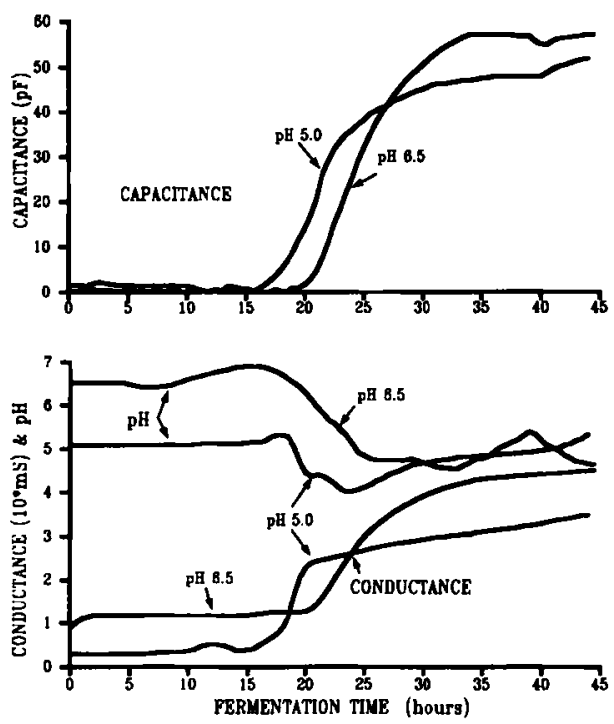

Fig 4. Effect of initial $\mathrm{pH}$ of quinoa on the changes in capacitance, conductance and $\mathrm{pH}$ during the tempe fermentation at a low inoculum density. Quinoa (sweet variety) at a moisture content of about $650 \mathrm{~g} \mathrm{~kg}^{-1}$ at $\mathrm{pH} 6.5$ and at $\mathrm{pH} 5.0$ (for preparation see Peñaloza 1991) were inoculated with $R$ oligosporus UFC-FF8001 at $3.5 \times 10^{3} \mathrm{cfu} \mathrm{g}^{-1}$. Incubation and monitoring were carried out as described in the legend to Fig 1.

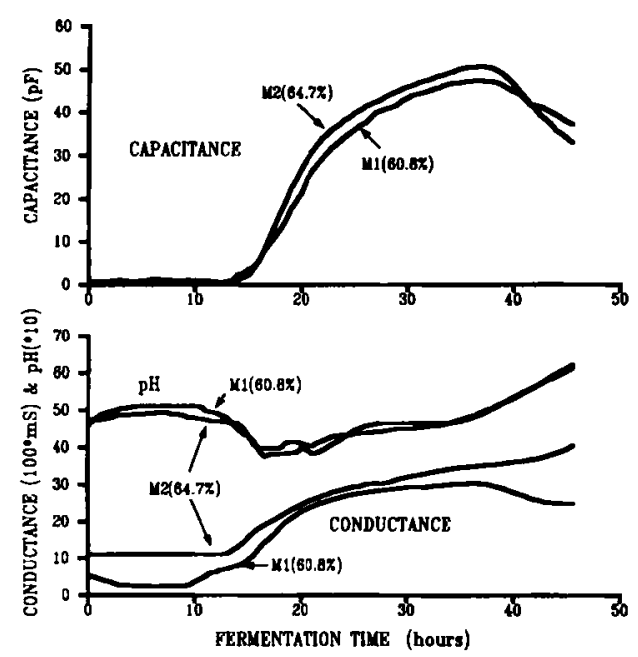

Fig 5. Changes in on-line capacitance, conductance and $\mathrm{pH}$ of a quinoa tempe fermentation at different initial moisture contents of the substrate. Sweet quinoa at an initial $\mathrm{pH}$ of $c 5$ (see legend to Fig 4), and at moisture contents $M 1\left(608 \mathrm{~g} \mathrm{~kg}^{-1}\right)$ and $\mathrm{M} 2\left(647 \mathrm{~g} \mathrm{~kg}^{-1}\right)$, were inoculated with $R$ oligosporus $\mathrm{UCW}$ FF8001 at $3.5 \times 10^{5} \mathrm{cfu} \mathrm{g}^{-1}$. Incubation and monitoring were as described in the legend to Fig 1.

Busse 1989, 1991; Mulyowidarso et al 1989, 1990) have all confirmed these results.

The stimulation by the lower $\mathrm{pH}$ of spore germination on sweet quinoa seems to be the most significant result in the present work, where bacterial contamination was neither sought nor found. In Fig 4 it may be observed that the lag phase is shortened by approximately $4 \mathrm{~h}$, but this difference becomes narrower and disappears by approximately $27 \mathrm{~h}$ incubation, after which the capacitance of mature tempe prepared from quinoa at high initial $\mathrm{pH}(6.5)$ is higher than that corresponding to an initial $\mathrm{pH}$ of $\mathbf{5 \cdot 0 \text { . }}$

The greater increase in capacitance for quinoa at an initial $\mathrm{pH}$ of 5.0 than at $\mathrm{pH} 6.5$ was associated with significantly different hyphal lengths after $24 \mathrm{~h}$ incubation, which were found to be $6.2 \mathrm{~km} \mathrm{~g}^{-1}$ and $2.6 \mathrm{~km} \mathrm{~g}^{-1}$, respectively.

One of the advantages of using cereals as a substrate for tempe is that, in contrast to soya (Steinkraus et al 1960) and other beans (Paredes-Lopez et al 1987, 1990), the $\mathrm{pH}$ falls within $24 \mathrm{~h}$ to 5.7 in wheat (Wang and Hesseltine 1966b), to $3 \cdot 0-4 \cdot 0$ in barley, oats, rye and others (Steinkraus 1983; Blakeman et al 1988) and from 6.5 to approximately 5 in quinoa (see Fig 4).

The increase of the $\mathrm{pH}$ of soya bean tempe is due to proteolysis (Steinkraus et al 1960; Paredes-Lopez et al $1987,1989)$. In cereal tempe fermentations, however, the formation of organic acids (and the consequent $\mathrm{pH}$ drop) gives a slightly sour product, with a distinctive, yeasty, fruit-like aroma (Steinkraus 1983), a feature also characteristic of quinoa tempe (see Peñaloza 1991).

\section{Effect of moisture content}

In the commercial manufacture of tempe in Malang, Indonesia, the time used for the superficial drying/ cooling of the beans varies from 1.45 to $7 \mathrm{~h}$ (Nout and Rombouts 1990). In consequence the moisture content of the soya beans is likely to vary widely; however, the relationship between the initial moisture content and the quality of tempe has not been precisely documented to date. For example, Steinkraus et al (1960) stated that the tempe mould would grow well only if the humidity around the beans was maintained at 'high level', but excess water allowed bacteria to develop, contributing off-odours to the tempe. Other authors used an initial moisture content of the substrate of around $453 \mathrm{~g} \mathrm{~kg}^{-1}$ in beans (Paredes-Lopez et al 1987), $650 \mathrm{~g} \mathrm{~kg}^{-1}$ in a mixture of cereals and pulses (Blakeman et al 1988), and $660 \mathrm{~g} \mathrm{~kg}^{-1}$ in wheat (Wang and Hesseltine 1966b).

The initial moisture content of quinoa before incubation, in the range between 600 and $650 \mathrm{~g} \mathrm{~kg}^{-1}$, had no significant effect on either the changes in capacitance, conductance and $\mathrm{pH}$ of sweet quinoa tempe (Fig 5) or on hyphal length, dry weight losses and increase of moisture content during the fermentation (see Table 2). At $44 \mathrm{~h}$ incubation, hyphal length was around $11 \mathrm{~km} \mathrm{~g}^{-1}$ of dried tempe, dry weight loss was $37 \%$ and moisture content of the tempe was about $700-740 \mathrm{~g} \mathrm{~kg}^{-1}$. For each parameter the slight differences observed were not significant. However, when the initial moisture content of quinoa was increased from 608 to $670 \mathrm{~g} \mathrm{~kg}^{-1}$, the lag phase was shortened by about $2 \mathrm{~h}$ (see Fig 6). In quinoa at a 
TABLE 2

Characteristics of tempe prepared from quinoa (Chenopodium quinoa) at several initial moisture contents

\begin{tabular}{|c|c|c|c|c|c|c|c|c|}
\hline \multirow{2}{*}{$\begin{array}{c}\text { Quinoa } \\
\text { moisture } \\
(\%)\end{array}$} & \multicolumn{4}{|c|}{$24 h$ incubation } & \multicolumn{4}{|c|}{$44 h$ incubation } \\
\hline & $\begin{array}{c}\mathrm{C} \\
(p F)\end{array}$ & $\begin{array}{c}\text { Hyphal } \\
\text { length } \\
\left(k m \mathrm{~g}^{-1}\right)\end{array}$ & $\begin{array}{c}\text { Dry wt loss } \\
(\%)\end{array}$ & $\begin{array}{c}\text { Moisture } \\
\left(g k^{-1}\right)\end{array}$ & $\begin{array}{c}\mathrm{C} \\
(p F)\end{array}$ & $\begin{array}{c}\text { Hyphal } \\
\text { length } \\
\left(k m g^{-1}\right)\end{array}$ & $\begin{array}{c}\text { Dry wt loss } \\
(\%)\end{array}$ & $\begin{array}{c}\text { Moisture } \\
\left(g k^{-1}\right)\end{array}$ \\
\hline \multicolumn{9}{|c|}{ Sweet quinoa inoculated with UCW-FF8001 at $3.5 \times 10^{4} c f u \mathrm{~g}^{-1}$} \\
\hline $61 \cdot 3$ & $39 \cdot 6^{a}$ & $8 \cdot 3$ & $14 \cdot 2$ & 657 & $48 \cdot 5^{a}$ & $12 \cdot 8$ & $36 \cdot 3$ & 719 \\
\hline $65 \cdot 2$ & $38 \cdot 6^{a}$ & $9 \cdot 2$ & $16 \cdot 2$ & 699 & $51 \cdot 6^{a}$ & $14 \cdot 1$ & $37 \cdot 6$ & 739 \\
\hline \multicolumn{9}{|c|}{ Bitter quinoa inoculated with UCW-FF8001 at $3.5 \times 10^{4} \mathrm{cfu} \mathrm{g}^{-1}$} \\
\hline $60 \cdot 8$ & $7 \cdot 6$ & - & - & - & $36 \cdot 4$ & $7 \cdot 3$ & $24 \cdot 6$ & 665 \\
\hline $67 \cdot 0$ & $18 \cdot 1$ & $7 \cdot 3$ & $12 \cdot 8$ & 703 & $30 \cdot 7$ & - & $38 \cdot 6$ & 775 \\
\hline \multicolumn{9}{|c|}{ Bitter quinoa inoculated with UCW-FF8002 at $3.5 \times 10^{4} \mathrm{cfu} \mathrm{g}^{-1}$} \\
\hline $62 \cdot 6$ & $15 \cdot 0$ & $6 \cdot 7$ & $10 \cdot 2$ & 652 & $32 \cdot 4$ & $12 \cdot 3$ & $39 \cdot 6$ & 735 \\
\hline $47 \cdot 1$ & $9 \cdot 5^{a}$ & $2 \cdot 7$ & $8 \cdot 8$ & 507 & $12 \cdot 1^{a}$ & $5 \cdot 5$ & $16 \cdot 8$ & 529 \\
\hline
\end{tabular}

The experimental conditions were exactly the same as described in the legend to Figs 5 and 6 . Other parameters are as described in the legend to Table 1.

- Data not available.

a Capacitance measured off-line at $0.30 \mathrm{MHz}$.
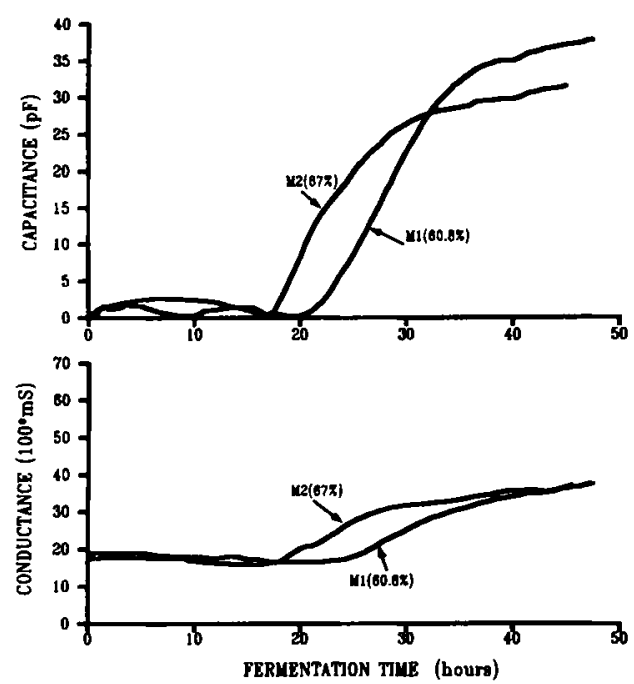

Fig 6. Monitoring of quinoa tempe fermentation at two initial moisture contents. Bitter quinoa at an initial $\mathrm{pH}$ of 6.5 and at moisture contents $608 \mathrm{~g} \mathrm{~kg}^{-1}(\mathrm{M} 1)$ and $670 \mathrm{~g} \mathrm{~kg}^{-1}$ (M2) were inoculated with $R$ oligosporus UCW-FF8001 at $3.5 \times 10^{4} \mathrm{cfu} \mathrm{g}^{-1}$. Incubation and monitoring were carried out as described in the legend to Fig 1.

moisture level of $670 \mathrm{~g} \mathrm{~kg}^{-1}$, although there is an early start to the fermentation, the capacitance of overfermented tempe is lower than that of tempe which was at an initial moisture content of $608 \mathrm{~g} \mathrm{~kg}^{-1}$ (see Fig 6). The lowest hyphal length $\left(2.7 \mathrm{~km} \mathrm{~g}^{-1}\right.$ of dry tempe) corresponds to the lowest moisture content tested $\left(471 \mathrm{~g} \mathrm{~kg}^{-1}\right)$ and also correlates with the lowest dry weight loss $(16.8 \%)$ and increase of moisture content $(6 \%)$ at the end of $44 \mathrm{~h}$ incubation at $31^{\circ} \mathrm{C}$ (see Table 2).
The sporulation of quinoa tempe was clearly affected by the initial moisture content. At initial moisture levels of $650 \mathrm{~g} \mathrm{~kg} \mathrm{k}^{-1}$ and above, sporulation of tempe at $24 \mathrm{~h}$ was nil and very light at $44 \mathrm{~h}$ incubation. Conversely, at moisture levels lower than $610 \mathrm{~g} \mathrm{~kg}^{-1}$, sporulation was noticeable at $20 \mathrm{~h}$ incubation, at $24 \mathrm{~h}$ it caused a grey ring of $5 \mathrm{~mm}$ thickness at the edge of the plates and also a slight internal sporulation (sporangia developed inside the tempe cake, ie between quinoa seeds), and at $44 \mathrm{~h}$ sporulation was so heavy that, in some cases (such as $471 \mathrm{~g} \mathrm{~kg}^{-1}$ moisture content), a grey to black tempe was obtained.

The taste, smell and appearance of tempe from quinoa at initial moisture contents of 610 and $650 \mathrm{~g} \mathrm{~kg}^{-1}$ were similar. However, an initial moisture content of $471 \mathrm{~g} \mathrm{~kg}^{-1}$ produced a very fragile cake. Conversely a watery tempe was obtained with quinoa at $670 \mathrm{~g} \mathrm{~kg}^{-1}$ moisture content.

Thus the ideal moisture content of quinoa prior to inoculation appears to be around $620 \mathrm{~g} \mathrm{~kg}^{-1}$. Although mycelial growth does occur over a wide range of initial moisture content of quinoa (at least from 470 to $\left.670 \mathrm{~g} \mathrm{~kg}^{-1}\right)$, the appearance of tempe is substantially affected. Sporulation was the major inconvenience at initial moisture contents lower than $610 \mathrm{~g} \mathrm{~kg}^{-1}$, and, on the contrary, a watery tempe was obtained when using quinoa with moisture contents above $640 \mathrm{~g} \mathrm{~kg}^{-1}$.

\section{Effect of quinoa variety}

The differences between bitter and sweet quinoa fermentations (see Fig 7) were not surprising. Hesseltine et al (1967) also noted that the mycelium varied between cereal varieties. The chemical composition of the two 

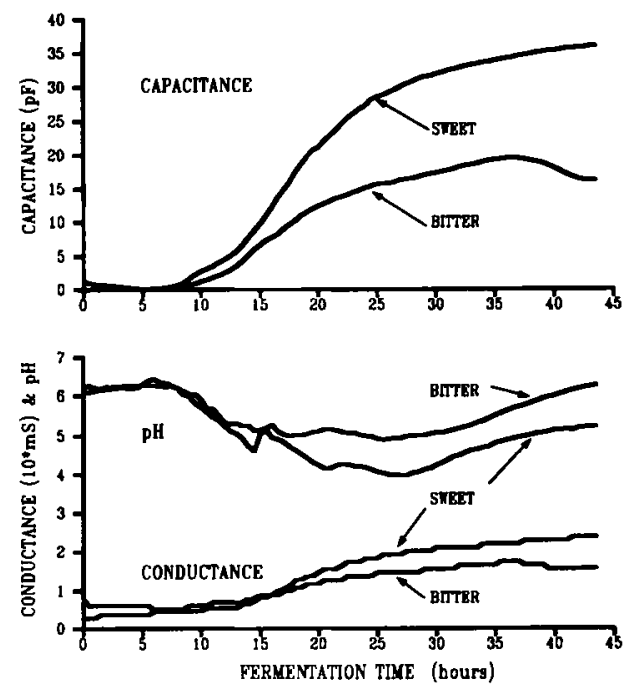

Fig 7. Changes of capacitance, conductance and $\mathrm{pH}$ of two varieties of quinoa during the tempe fermentation. Quinoa varieties sweet and bitter, both at a moisture content of about $640 \mathrm{~g} \mathrm{~kg}^{-1}$ and a pH of 6.5 , were used in the tempe fermentation. Other conditions were exactly as described in the legend to Fig 5.

quinoas (Koziol 1990) was similar and unlikely to account for the lower capacitance in tempe from bitter quinoa. Such differences might be due to the substrate-mould interaction in the system, eg hyphal penetration might be different in the two quinoas. However, it is also plausible that the lower capacitance attained in the bitter quinoa fermentation may be related to the loss of important nutrients during the preparation of the substrate, since Peñaloza et al (1991) could relate the poor mycelial quality in a bitter lupin tempe fermentation to the loss of $\mathrm{K}^{+}$during the lengthy preparation phase necessary for this substrate.

\section{CONCLUSIONS}

The study reported here has confirmed the usefulness of on-line measurements of the radio-frequency electrical capacitance for determining the mycelial biomass in the solid-substrate tempe fermentation. It has also proved possible to use this as an effective and convenient method for defining the best conditions in which quinoa may be used as a substrate for the tempe fermentation. By using the petri dish as a model system it transpired that the optimal combination of strain and fermentation condition was an initial moisture content of some $620 \mathrm{~g} \mathrm{~kg}^{-1}$, an initial $\mathrm{pH}$ of 6.4 , and an inoculum of $3 \times 10^{4} \mathrm{cfu}$ of strain UCW-FF8001 $\mathrm{g}^{-1}$ substrate. We conclude that it is very probable that these parameters also apply to other fermentation systems with a similar quinoa cake thickness in which the conditions are controlled in a similar way. Commercial tempe production from quinoa does not yet exist, but we believe that the results presented here will provide the stimulus for such a development.

\section{ACKNOWLEDGEMENTS}

We thank the Biotechnology Directorate of the Science and Engineering Research Council, UK, the British Council and Universidad Tecnica de Ambato for financial support, Aber Instruments for the use of a Bugmeter Biomass Monitor, and Latinreco SA for the supply of quinoa.

\section{REFERENCES}

Ashenafi M, Busse M 1989 Inhibitory effect of Lactobacillus plantarum on Salmonella infantis, Enterobacter aerogenes and Escherichia coli during tempeh fermentation. $J$ Food Prot 52 169-172.

Ashenafi M, Busse M 1991 Growth of Bacillus cereus in fermenting tempeh made from various beans and its inhibition by Lactobacillus plantarum. J Appl Bacteriol 70 329-333.

Blakeman J P, McCracken A R, Seaby D A 1988 Changes brought about in solid substrates after fermentations of mixtures of cereals and pulses with Rhizopus oryzae. J Sci Food Agric 45 109-118.

Carruthers S P 1986 Alternative Enterprises for Agriculture in the $U K$ Centre for Agricultural Strategy, University of Reading, pp 42-46.

Cotter D A 1981 Spore activation. In: The Fungal Spore: Morphogenetic Controls eds Turian G \& Hohl H R. Academic Press, London, pp. 385-407.

Davey C L, Markx G H, Kell D B 1990 Substitution and spreadsheet methods for analysing dielectric spectra of biological systems. Eur Biophys $J 18$ 255-265.

Davey C L, Peñaloza W, Kell D B, Hedger J N 1991 Real-time monitoring of the accretion of Rhizopus oligosporus biomass during the solid-substrate tempe fermentation. World $J$ Microbiol Biotechnol 7 248-259.

Gandjar I 1986 Soybean fermentation and other tempe products in Indonesia. In: Indigenous Fermented Food of nonWestern Origin, eds Hesseltine C W \& Wang H L. J Cramer, Berlin, pp 55-66.

Gow N A R 1989 Relationship between growth and the electrical current of fungal hyphae. Biol Bull 176S 31-35.

Harris C M, Todd R W, Bungard S J, Lovitt R W, Morris J G, Kell D B 1987 The dielectric permittivity of microbial suspensions at radio frequencies: a novel method for the real-time estimation of microbial biomass. Enzyme Microbial Technol 9 181-186.

Hesseltine CW, Smith M, Bradle B, Ko S D 1963 Investigations on tempeh, an Indonesian food. Devel Ind Microbiol $4275-287$.

Hesseltine C W, Smith M, Wang H L 1967 New fermented cereal products. Devel Ind Microbiol 8 179-186.

Kell D B, Markx G H, Davey, C L, Todd R W 1990 Real-time monitoring of cellular biomass: methods and applications. Trends Anal Chem 9 190-194.

Kidby D K, McComb J R, Snowdon R L, Garcia-Web P, Gladstones J S 1977 Tempeh production from Lupinus angustifolius L. In: Fifth Int Conf Global Aspects of Applied Microbiology, Bangkok. UNEP/UNESCO/ICRO.

Ko S D, Hesseltine C W 1979 Tempe and related foods. In: 
Economic Microbiology, Vol 4, ed Rose A H Academic Press, London, pp 115-140.

Koziol M 1990 Composicion quimica. In: Quinua hacia su Cultivo Comercial, ed Wahli C. Latinreco S A Nestlé, Quito, pp 137-159.

Liem I T H, Steinkraus K H, Cronk T C 1977 Production of vitamin B-12 in temped, a fermented soybean food. Appl Environ Microbiol 34 773-776.

Markx G H, Kell D B 1990 Dielectric spectroscopy as a tool for the measurement of the formation of biofilms and of their removal by electrolytic cleaning pulses and biocides. Biofouling 2 211-227.

Markx G H, Davey C L, Kell D B 1991 The permittistat: a novel type of turbidostat. J Gen Microbiol 137 735-743.

Mizui F, Kasai R, Ohtani K, Tanaka O 1990 Saponins from bran of quinoa, Chenopodium quinoa Willd. II. Chem Pharm Bull 38 375-377.

Mulyowidarso R K, Fleet G H, Buckle K A 1989 The microbial ecology of soybean soaking for tempe production. Int J Food Microbiol 8 35-46.

Mulyowidarso R K, Fleet G H, Buckle K A 1990 Association of bacteria with the fungal fermentation of soybean tempe. $J$ Appl Bacteriol 68 43-47.

Nout M J R, Bonants-Van Laarhoven T M G, De Dreu R, Gerats I A G M 1985 The influence of some process variables and storage conditions on the quality and shelflife of soya bean tempeh. Antonie van Leeuwenhoek 51 532-534.

Nout M J R, Beernink G, Bonants-Van Laarhoven T M G 1987a Growth of Bacillus cereus in soya bean tempeh. Int $J$ Food Microbiol 4 293-301.

Nout M J R, De Dreu M A, Zuurbier A M, Bonants-Van Laarhoven T M G 1987b Ecology of controlled soya bean acidification for tempe manufacture. Food Microbiol 4 165-172.

Nout M J R, Notermans S, Rombouts F M 1988 Effect of environmental conditions during soya bean fermentation on the growth of Staphylococcus aureus and the production and thermal stability of enterotoxins $A$ and B. Int $J$ Food Microbiol 7 299-309.

Nout M J R, Rombouts F M 1990 A review, recent developments in tempe research. $J$ Appl Bacteriol 69 609-633.

Paredes-Lopez O, Harry G I, Montes-Rivera R 1987 Development of a fermentation procedure to produce a temperelated food using common beans as substrate. Biotechnol Lett 9 333-338.

Paredes-Lopez O, Harry G I, Gonzalez-Castaneda J 1990 Sensory evaluation of tempeh produced by fermentation of common beans. J Food Sci 55 123-126.

Peñaloza W 1991 Studies on the tempe fermentation of Andean pulses. PhD thesis, University College of Wales.
Peñaloza W, Davey C L, Hedger J N, Kell D B 1991 Stimulation by potassium of the growth of Rhizopus oligosporus during liquid- and solid-substrate fermentations. World J Microbiol Biotechnol 7 260-268.

Reichert R D, Tatarynovich J T, Tyler R T 1986 Abrasive dehulling of quinoa (Chenoposium quinoa): effect on saponin content as determined by an adapted hemolytic assay. Cereal Chem 63 471-475.

Risi J C, Galwey N W 1984 The Chenopodium grains of the Andes: Inca crops for modern agriculture. Adv Appl Biol 10 145-216.

Robalino D, Peñaloza W 1988 Uso de la quinua en la elaboracion de tempe. In: Resumenes del VI Congreso Internacional sobre Cultivos Andinos, Quito, Instituto Nacional de Investigaciones Agropecuarias, Quito, p. 42.

Robinson P 1978 Practical Fungal Physiology. Wiley, Chichester, pp. 1-18.

Robinson R J, Kao C 1977 Tempeh and miso from chickpea, horse bean, and soybean. Cereal Chem 54 1192-1197.

Samson R A, Van De Kooij J A, Boer E 1987 Microbial quality of commercial tempeh in The Netherlands. $J$ Food Prot 50 92-94.

Steinkraus K H 1983 Indonesian tempe and related fermentations: protein-rich vegetarian meat substitutes. In: Handbook of Indigenous Fermented Foods, eds Steinkraus K H, Cullen R E, Pederson C S, Nellis LF \& Gavitt B K. Marcel Dekker, New York, pp 1-94.

Steinkraus K H, Hwa Y B, van Buren J P, Providenti M I, Hand D B 1960 Studies on tempe-an Indonesian fermented soybean food. Food Res 25 777-788.

Tanaka N, Kovats S K, Guggisberg J A, Meske L M, Doyle M P 1985 Evaluation of the microbiological safety of tempeh made from unacidified soybeans. $J$ Food Prot 48 438-441.

Wahli C 1990 Quinoa Hacia su Cultivo Comercial. Latinreco S A Nestlé, Quito.

Wang H L, Hesseltine C W 1966a Studies on the extracellular proteolytic enzymes of Rhizopus oligosporus. Can J Microbiol 11 727-732.

Wang H L, Hesseltine C W 1966b Wheat tempeh. Cereal Chem 43 563-570.

Wang $\mathrm{H} \mathrm{L}$, Hesseltine C W 1979 Mold-modified foods. In: Microbial Technology (2nd edn), Vol II, ed Peppler H J \& Perlman D. Academic Press, London, pp 95-129.

Wang H L, Swain E W, Hesseltine C W 1975 Mass production of Rhizopus oligosporus spores and their application in tempeh fermentation. $J$ Food Sci 40 168-170.

Williams A P, Wood J M 1986 Impedimetric estimation of moulds. In: Methods for the Mycological Examination of Food, ed King Jr A D, Pitt J I, Beuchat L R \& Corry J E L. Plenum Press, New York, pp 230-238. 